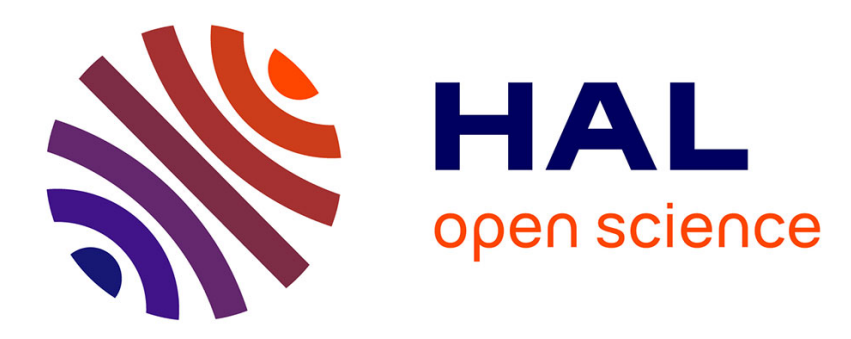

\title{
Plant ecological indicator values as predictors of fine-root trait variations
}

Florian Fort, Gregoire T. Freschet

\section{To cite this version:}

Florian Fort, Gregoire T. Freschet. Plant ecological indicator values as predictors of fine-root trait variations. Journal of Ecology, 2020, 108 (4), pp.1565-1577. 10.1111/1365-2745.13368 . hal-02987244

\section{HAL Id: hal-02987244 \\ https://hal.science/hal-02987244}

Submitted on 5 Nov 2020

HAL is a multi-disciplinary open access archive for the deposit and dissemination of scientific research documents, whether they are published or not. The documents may come from teaching and research institutions in France or abroad, or from public or private research centers.
L'archive ouverte pluridisciplinaire HAL, est destinée au dépôt et à la diffusion de documents scientifiques de niveau recherche, publiés ou non, émanant des établissements d'enseignement et de recherche français ou étrangers, des laboratoires publics ou privés. 


\section{Journal of Ecology}

2 MR FLORIAN FORT (Orcid ID : 0000-0001-7983-6254)

3

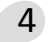

5 Article type : Research Article

6 Editor : Hans de Kroon

7

8

9 Plant ecological indicator values as predictors of fine-root trait variations

10

11 Florian Fort*a, Grégoire T. Freschet ${ }^{\mathrm{b} \dagger}$

12

13 a CEFE, Montpellier SupAgro, Université de Montpellier, Université Paul Valéry, EPHE, IRD, 1919 route 14 de Mende, 34293 Montpellier Cedex 5, France

15 b CEFE, CNRS, Université de Montpellier, Université Paul Valéry, EPHE, IRD, 1919 route de Mende, $16 \quad 34293$ Montpellier Cedex 5, France

17 present address : Station d'Ecologie Théorique et Expérimentale UMR 5321, CNRS and Paul Sabatier 18 University, 2 route du CNRS, 09200 Moulis, France

$19 *$ corresponding author: Florian Fort

20 e-mail: florian.fort@supagro.fr

21 corresponding author address: Montpellier SupAgro, 2 place Pierre Viala, 34060 Montpellier, FRANCE

This article has been accepted for publication and undergone full peer review but has not been through the copyediting, typesetting, pagination and proofreading process, which may lead to differences between this version and the Version of Record. Please cite this article as doi: $\underline{10.1111 / 1365-2745.13368}$

This article is protected by copyright. All rights reserved 


\section{Abstract}

24 1. Fine-roots play key roles in the capacity of plants to face environmental constraints and their traits reflect 25 adaptations to the environment, including soil structure, resource availability and climate. However, the 26 inaccuracy of global soil and climate databases to account for the large environmental variation occurring 27 at small spatial scale prevents accurate estimations of the linkages between environmental variables and 28 fine-root strategies.

29 2. Here, using two global databases on fine-root traits (Rhizopolis-db) and species phylogenetic 30 relatedness, and a regional database of species ecological indicator values (Baseflor), we quantified the 31 predictive value of ecological indicator values, as an alternative to classical coarse soil and climate 32 indicators, on the variation in four major fine-root traits.

33 3. A strong phylogenetic signal was found among species for fine-root mean diameter, specific root length 34 (SRL) and root tissue density (RTD), but less so for root nitrogen concentration (RNC). After accounting 35 for this relatedness, ecological indicators still explained a large part of trait variation in our dataset for SRL, 36 RTD and RNC. Multi-indicators best model $R^{2}$ reached 0.40 for SRL and RTD, and 0.44 for RNC, whereas 37 it was only 0.10 for diameter. Ecological indicators of nutrient availability and soil texture were those that 38 most strongly related to SRL, RTD and RNC. Specifically, plant fast resources use strategies characterized 39 by high SRL, RNC and low RTD occurred more frequently in nutrient-rich soils and in soils with light 40 sandy textures. Additionally, light availability and atmospheric temperature were negatively related with 41 SRL and continentality negatively influenced RNC.

42 4. With respect to both nutrient and water availability ecological indicator values, opposite adaptations 43 were observed between growth forms, particularly between woody and herbaceous species, limiting our 44 ability to define simple, widely applicable patterns of trait-environment relationships.

45 Synthesis: Our analysis demonstrates that species ecological indicator values are valuable predictors of 46 plant below-ground strategies. It provides original evidence that herbaceous species with fine-root traits 47 representative of fast resource use strategies typically occur in more favourable soil habitats (high nutrient 48 and water availability), meanwhile woody species may show the opposite trend. Other important 49 environmental parameters concomitantly influence fine-root trait variation in contrasting ways.

51 Key words: Plant-climate interactions, Plant-soil (below-ground) interactions, Ecological indicator values 52 (EiV), Environmental gradients, Fine-root traits, Root nitrogen concentration, Root tissue density, Specific 53 root length 
56 Understanding the strategies that allow species to establish and sustain a population in a habitat is a central

57 goal in ecology (Craine, Froehle, Tilman, Wedin \& Chapin, 2001; Grime, 1977; Westoby, 1998). Plant

58 functional traits (sensu Violle et al. 2007) reflect species evolutionary history and, as a result, their

59 adaptation to a large range of environmental constraints (Cavender-Bares, Kozak, Fine, \& Kembel, 2009;

60 Grime, 1977; McGill, Enquist, Weiher, \& Westoby, 2006). They are key descriptors of plant strategies, by

61 controlling their capacity to pass through environmental and biotic filters (Keddy, 1992; Lortie et al.,

62 2004), and to sustain a population at the intersection of various environmental gradients (Reich, 2014). As

63 such, strong links have been previously identified at the global scale between the position of species

64 ecological niche (Hutchinson, 1957) along environmental gradients and their functional traits (Freschet et

65 al., 2017; Jager, Richardson, Bellingham, Clearwater, \& Laughlin, 2015; Maire et al., 2015; Moles et al.,

66 2014; Ordoñez et al., 2009). Nonetheless, much remains to be done to refine our understanding of these

67 linkages, particularly with respect to plant below-ground features (Freschet et al., 2017; Iversen et al., 68 2017).

69 From works on above-ground parts of plants, we know that species from environments with high nutrient

70 availability generally display fast resource acquisition strategies characterised by low leaf tissue density,

71 high specific leaf area (SLA) and high leaf nutrient concentration (Jager et al., 2015; Janse-Ten Klooster,

72 Thomas, \& Sterck, 2007; Ordoñez et al., 2009). A contrasting trend occurs however with respect to light

73 availability, as species adapted to full light conditions generally harbour lower SLA than species from low

74 light conditions (Janse-Ten Klooster et al., 2007; Niinemets, 2010; Vojtkó et al., 2017). Besides these

75 patterns associated to critical above- and below-ground resources, leaf traits are also known to vary with

76 many other environmental factors such as temperature, precipitation, aridity or climatic extremes (Maire et

77 al., 2015). Above- and below-ground reproductive traits (e.g. seed mass, bud bank characteristics) also vary

78 according to environmental gradients (Herben, Tackenberg, \& Klimešová, 2016; Vojtkó et al., 2017).

79 Vojtkó et al. (2017) demonstrated at the community level that bud bank size and depth are lower for

80 communities from habitats with high light and nutrient availability, whereas high moisture tends to have

81 the opposite effect. Parallel knowledge of the environmental drivers of species root trait variation is less

82 clear and appears to date largely inconsistent. On the one hand, tree species from more fertile habitats have

83 been shown to have lower specific root length (SRL) (Kramer-Walter et al., 2016; Ostonen et al., 2007),

84 lower root tissue density (RTD), higher mean fine-root diameter and no difference in root nitrogen

85 concentration (RNC) as compared to species of less fertile habitats (Kramer-Walter et al., 2016). On the

86 other hand, studies mostly based on graminoid and forb species highlighted a decrease in species RTD and

87 fine-root diameter and an increase in SRL and RNC with increasing habitat fertility (Craine et al., 2001;

88 Fort et al., 2016; Ryser, 1996). This was also confirmed by studies measuring root traits over entire

This article is protected by copyright. All rights reserved 
89 communities (i.e. community functional parameter; Prieto et al., 2015; Fort et al., 2016). These contrasting

90 results suggest that plants of distinct growth forms or phylogenetic groups may not respond homogeneously

91 to the same environmental gradients.

92 Recently, two meta-analyses on fine roots and very fine roots (Freschet et al., 2017; Valverde-Barrantes et

$93 a l ., 2017$, respectively) suggested that climate conditions relate to fine-root traits representative of soil

94 resource acquisition, with a particularly strong positive effect of temperature on fine-root diameter and

95 negative effect on SRL, and a negative effect of rainfall on RNC. However, relationships between fine-root

96 traits and soil properties were more ambiguous (Freschet et al., 2017), likely owing to the use of coarse-

97 scale soil data inadequate to capture fine-scale soil heterogeneity. Most root studies and therefore root

98 databases are lacking a common set of descriptors of soil properties (Iversen et al., 2017). Therefore, while

99 current knowledge on the climatic drivers of species root trait values contrasts with expectations from the

100 "fast-slow" root economics spectrum theory (Reich, 2014; Weemstra et al., 2016), our understanding of

101 soil drivers of root trait values remains largely incomplete. This is despite fine-scale environmental

102 variations, particularly in soil properties, are known to have strong effects on species traits (e.g. Freschet,

103 Cornelissen, van Logtestijn, \& Aerts, 2010; Hill, Simpson, Moore, \& Chapman, 2006) and community

104 functional parameters (i.e., trait values measured at the plant community level) (Fort et al., 2016) and may

105 mitigate the effects of more global environmental gradients (Conti, de Bello, Lepš, Acosta, \& Carboni, 106 2017). Acknowledging the limitation of current global root trait and soil databases regarding soil 107 properties, one way to gain further insight into the relationships between species root traits and 108 environmental features is to assess linkages between species trait values and species ecological indicator 109 values (Ellenberg et al., 1991; Garnier et al., 2016).

110 Ecological indicators values (EiV), generally established at the regional scale, characterise the ecological 111 optimum of species along major environmental gradients using ordinal scales. They are highly useful 112 indices to assess species niche position along environmental gradients without direct measurement 113 (Bartelheimer \& Poschlod, 2016; Diekmann, 2003; Herben et al., 2016). These EiV are derived from long114 term vegetation surveys, expert knowledge and measurements of soil parameters. They reflect 115 environmental conditions where a plant species is most likely to sustain a population, i.e. species optimal 116 niche position along environmental gradients (Bartelheimer \& Poschlod, 2016; Fort, Jouany, \& Cruz, 2015; 117 Silvertown, Dodd, Gowing, Lawson, \& McConway, 2006). Since species EiV are estimated across entire 118 populations of individuals occurring across a range of environments, they can be meaningfully related to 119 trait data coming from heterogeneous databases where traits have been measured in a range of growth 120 conditions. Recent studies highlighted that EiV are related with key functional traits, such as relative 121 growth rate, net carbon assimilation rate, and reproductive strategies (Bartelheimer \& Poschlod, 2016; 122 Herben et al., 2016; Shipley et al., 2017). Bartelheimer \& Poschlod (2016) demonstrated for instance a 
123 positive relationship between EiV related to nutrient availability, $\mathrm{pH}$ and soil water and plant relative 124 growth rate and SLA, and a negative relationship between light availability EiV and these same traits. 125 Vojtkó et al. (2017) confirmed further the robustness of these relations between SLA and nutrient, $\mathrm{pH}$ and 126 light EiV at the community level. The relationships between these traits and EiV were however weaker for 127 continentality and temperature (Bartelheimer \& Poschlod, 2016; Vojtkó et al., 2017) and the relationship 128 between SLA and light or water EiV appeared to be impacted by plant growth form (Shipley et al., 2017). 129 Except for reproductive and regenerative traits (Herben et al., 2016; Vojtkó et al., 2017), relationships 130 between EiV and plant strategies were for most part established based on plant above-ground 131 characteristics, highlighting above-ground level adaptations to species niche along environmental gradients 132 (Bartelheimer \& Poschlod 2016 and references therein). However, root system characteristics represent key 133 aspects of species adaptation to various environmental constraints and especially soil resources (Bauhus \& 134 Messier, 1999; Forde \& Lorenzo, 2001; Ostonen et al., 2007). In this context, extending the known 135 relationships between EiV and plant characteristics to below-ground traits would be critical to further our 136 understanding of processes driving the differentiation of species ecological niches.

137 The general aim of this study was to determine i) whether fine-root traits representing different aspects of 138 root resource use strategies are related to species niche position along environmental gradients. More 139 specifically, we hypothesised that ii) fine-root traits would be most related with nutrient and water 140 availability EiV, due to the central role of roots in the uptake of these resources; and that iii) species with 141 fine-root traits favouring fast soil resource use (high SRL and RNC, low RTD and fine-root diameter) 142 would typically occur in environments with favourable soil conditions (high nutrient and water availability, 143 low soil density).

144 To test these hypotheses, we studied the relationships between four fine-root traits (fine-root diameter, 145 RNC, RTD and SRL) of ecological importance (Freschet \& Roumet, 2017), as taken from a worldwide 146 database of fine-root traits (Rhizopolis-db; Freschet et al. 2017), and species ecological niche position 147 along environmental gradients across 249 species with available EiV (Julve, 2015), accounting for species 148 phylogenetic relatedness.

This article is protected by copyright. All rights reserved 


\section{Materials and Methods}

\section{DATA COLLECTION}

151 The first step of our study was to collect functional trait data using a global database of fine-root traits 152 spanning 1115 species (Rhizopolis database; Freschet et al., 2017). We restricted our selection of species to 153 these presenting at least one of the four most commonly measured root functional traits: root diameter, 154 SRL, RTD and RNC. To improve the homogeneity of our trait data, we further restricted our selection of 155 species to those with roots sampled as $<2 \mathrm{~mm}$ in diameter (i.e., the most common sampling classification in 156 our database; Freschet \& Roumet 2017). The trait data were categorized, depending on species growth 157 conditions, as in "pot" (indoors or outdoors), in "common garden" (outdoor plantations) or in "field" 158 conditions (natural conditions), in order to differentiate between different degrees of climate and soil 159 manipulation.

160 The second step was to cross species root trait data with EiV data from the Baseflor database (Julve, 2015). 161 Baseflor is a floristic database indexing about 10,000 taxa from the French vascular flora. For each taxon, 162 the database includes ecological, and biological descriptions (Julve, 2015). In the Baseflor database, the F, 163 K, L, N, R and T Ellenberg's indicators values (Ellenberg et al., 1991) are modified to take into account the

164 French ecological context of each taxon, and extended to species typical of the French flora. Additionally, 165 soil organic matter content, soil texture and atmospheric humidity EiVs were established using the same 166 methodology as Ellenberg's indicators values (Ellenberg et al., 1991) based an extensive collection of data 167 on species ecology coming from flora and others published sources, the author's field experience and 168 scientific exchanges with ecologists, especially phytosociologists (Julve, 2009). The relationships between 169 Baseflor EiV and original Ellenberg's EiV, for a common subset of species and EiV, are strong, with $R^{2}$ 170 ranging from 0.32 for continentality to 0.84 for $\mathrm{pH}$ and Temperature EiVs ( $p$-value $<0.001$, Fig. S1) 171 Baseflor also includes additional EiV describing climate, i.e. atmospheric moisture, and soil characteristics, 172 i.e. soil texture and organic matter content, which are of strong interest for explaining root traits. Species 173 from the Rhizopolis database (Freschet et al., 2017) were crossed with the EiV database to identify species 174 presenting both types of data. Based on this selection of 357 species, we identified nine EiV for which we 175 had enough observations to perform robust analyses. These EiV could be separated into three groups: i) 176 EiV related to resource availability, i.e. light, nutrients and soil water; ii) EiV related to climate, i.e. 177 atmospheric humidity, continentality and temperature, and iii) EiV related to soil properties, i.e. $\mathrm{pH}$, 178 organic matter content and soil texture. For resource availability, low EiV indicate low resource 179 availability, whereas high values indicate high resource availability. For climatic conditions, low EiV for 180 atmospheric moisture and temperature indicate low air humidity and temperature, whereas high EiV 181 indicate high air humidity and temperature, respectively; low values of continentality indicate that species 182 occurred in oceanic habitats, whereas high values indicate that species occurred in continental habitats. For 
183 soil properties, low $\mathrm{pH}$ and organic matter EiV indicate acid $\mathrm{pH}$ and low organic matter content, whereas 184 high EiV indicate high $\mathrm{pH}$ and organic matter content, respectively; low EiV of soil texture indicate that 185 species occurred in loamy soil, whereas value around 5 indicate that species occurred in sandy soil and 186 values higher than 6 indicate that species occurred in scree or stone. Repartition of species among the EiV 187 were provided in the Figure S2. Non-surprisingly, the median classes of EiV were most represented, 188 whereas extreme EiV had fewer observations. This trend was particularly pronounced for low temperature, 189 low light availability and high soil texture EiV (species from gravel and stone habitats) and less so for 190 nutrient and organic matter EiV (Fig. S2). This may result from the fact that a limited number of species 191 have their ecological optimum in extreme environmental conditions (although present in extreme 192 environments), but also from the lack of studies on roots in extreme habitats.

193 In order to estimate the phylogenetic signal on species root traits and take it into account in our analyses we 194 constructed a phylogenetic tree using the comprehensive species-level phylogeny from Zanne et al. (2014), 195 as updated by Qian \& Jin (2016). This time-calibrated tree includes nearly all families of extant seed plants: 196 species placement relied on seven gene regions, with orders and families constrained by the APG III 197 (2016). We used S.PhyloMaker (Qian \& Jin, 2016) to generate a phylogeny containing species from the 198 Rhizopolis database from this megaphylogeny. Where species or genera were not represented in the larger 199 tree, they were added as uninformative (e.g. basal) polytomies. The final tree was ultrametric with time200 calibrated branches.

201

202 As a result, we selected 249 species from 62 families (Fig. 1) and from 34 datasets for which we collected 203 at least one mean value of one of the four traits (root diameter, SRL, RTD, RNC), the nine values of the 204 ecological indicators and the position along the phylogenetic tree. This represented 218 species for SRL, 205182 for fine-root diameter, 172 for RTD and 144 species for RNC (Table 1).

\section{6}

\section{Data analysis}

208 Recent papers have highlighted the importance of phylogenetic corrections for meta-analyses and similar 209 comparative analyses (Chamberlain et al., 2012), as it can represent a significant source of non210 independence between observations. We tested for phylogenetic signal (Pagel's $\lambda$ ) in the values of each of 211 the four root traits (phylosig() in 'phytools' (Revell, 2012)). Values of Pagel's $\lambda$ close to zero indicate 212 phylogenetic independence and larger values (approaching 1) indicate increasingly strong relationships 213 between trait values and the phylogeny (Münkemüller et al., 2012).

214 The potential effects of plant growth conditions and datasets were corrected using a random-effect model

215 with growth condition and dataset as random factors to calculate a best linear unbiased predictor (BLUP) of 
216 the log-transformed mean trait value of each species and its standard error (see Freschet et al., 2017). The 217 BLUP were calculated with mixed linear models (lmer() in 'Ime4' package; Bates, Mächler, Bolker, \& 218 Walker, 2015). We then examined the link between the estimated species trait values (BLUP) and species 219 habitat position along ecological gradients (i.e. EiVs) by using a model averaging procedure (Johnson \& 220 Omland, 2004). Models used within this procedure are general least square (gls) models in which the 221 correlation structure is a phylogenetic tree reflecting the evolutionary relationships between all species 222 present in the dataset (using gls() from 'nlme' package; Pinheiro, Bates, DebRoy, Sarkar, \& Team, 2016). 223 These models recognize that trait values may have non-zero covariances between them as a result of shared 224 evolutionary history between species, and so transform the data to reflect this. Linear regression is then 225 applied to the transformed data (Stone, Nee, \& Felsenstein, 2011). The weight of each species within the 226 models was proportional to the inverse of the standard error of its BLUP to take into account the 227 uncertainty of the mean trait value estimates. For each trait, the complete models included all the EiV. The 228 set of all possible models were run and ranked according their corrected Akaike information criterion 229 (AICc) (using dredge() from 'MuMin' package; Bartoń, 2016). For each trait, we first extracted the results 230 of the best model (based on AICc). Then, we estimated the effect of each EiV on each trait by calculating 231 the means and confidence intervals (95\%) of the estimates associated with the EiV among the models 232 representing $95 \%$ of the total AICc weight. The relative importance (RI) of EiV effect on trait values was 233 estimated by the sum of the AICc weights of the models in which the EiV appears (the more the RI value of 234 an ecological indicator is close to 1 the more the models where it is represented have high AICc weights, 235 i.e. represent well the fitted data). For each trait the best model was used to calculate an $\mathrm{R}^{2}$ with the method 236 proposed by Nakagawa \& Schielzeth (2013). The same procedure of model selection was also conducted 237 independently for each plant growth form to test the effect of plant growth forms on the relationship 238 between trait values and EiV.

239 Finally, to test the multivariate relationship between the set of root traits and EiV we performed a 240 phylogenetic canonical correlation analysis (pCCA, using phyl.cca() in 'phytools'; Revell, 2012) on a 241 subsample of 68 species for which we had BLUP values for each of the four traits. 


\section{Results}

\section{Phylogenetic signal}

245 All four traits showed large and significant $(p$-value $<0.001)$ phylogenetic signals (Fig. 1, Table 1). SRL 246 showed the strongest signal with a Pagel's $\lambda$ of 0.84 , whereas RNC had the weakest signal with a Pagel's $\lambda$ 247 of 0.59 . This was consistent with significant differences in root traits among species and families (Fig. 1, 248 Fig. S3). Brasicaeae and Poaceae families displayed the thinnest roots (highest SRL and low diameter) 249 whereas Cistaceae, Fagaceae and Oleaceae had the coarsest roots within the dataset. Fabaceae were 250 characterized by their low RTD and high RNC (Fig. 1, Fig. S3).

\section{Ecological indicators}

252 Ecological indicator values were good estimators of RNC ( $R^{2}$ of the best model (AIC-based) equal to 0.45$)$, 253 SRL and RTD (best model $R^{2}$ of 0.41 and 0.40 , respectively). All three traits appeared to be related to at 254 least four ecological indicators (Fig. 2). In contrast, fine-root diameter was only modestly estimated by EiV 255 (for the best model $R^{2}=0.11$ ) and was significantly related to one EiV only (Fig. 2; Table S1). These 256 results were impacted by species growth form (Fig. 2), as discussed in more detail below.

257 Among ecological indicators related with climate, continentality EiV had a strong negative effect on RNC 258 for both the whole dataset and grasses only, highlighting that species from continental climate had lower 259 RNC than species from more oceanic conditions (Fig. 3). Continentality also had a negative effect on the 260 mean root diameter of shrubs and trees, highlighting that woody species from continental habitats had 261 thinner absorptive roots than woody species from oceanic habitats (Fig. 3). Atmospheric humidity EiV had 262 a positive effect on RTD and RNC, indicating that species generally present in humid climates displayed 263 higher RTD and RNC than average, independently of their phylogenetic relatedness (Fig. 3). The same 264 relation was observed when grasses were analysed alone, but the estimates did not significantly differ from 265 zero for other growth forms (Fig. 3). Finally, the temperature EiV had a negative influence on SRL, 266 indicating that species from cold environments generally displayed higher SRL than average. At the level 267 of growth forms, temperature had a negative effect on root diameter of trees, and displayed contrasting 268 effects on the RNC of grasses and forbs: i.e. grass species from cold habitats had higher RNC than grasses 269 from warmer habitats, whereas the opposite trend occurred for forbs (Fig. 3).

270 Among EiV related to resource availability, nutrient EiV had strong effects ( $R I \geq 0.94)$ on SRL, RNC and 271 RTD. Across all species, plants found in nutrient-rich soils had higher SRL and RNC and lower RTD 272 values than species from nutrient-poor soils. At the level of plant growth forms, grasses and forbs showed 273 the same trend than at the whole dataset level, whereas trees displayed lower diameter, higher SRL and 274 RNC values at lower nutrient EiV. Soil water EiV had a strong and negative effect on RTD and RNC for 
275 both the whole dataset and grasses only, showing that species from environments with high water 276 availability or water-logged environments had lower RTD and RNC than other species. In contrast, tree and 277 shrub species analysed separately displayed higher RNC values, and forbs displayed lower diameter and 278 SRL values in case of high water EiV. Light EiV was negatively related with SRL and positively related 279 with root diameter, indicating that species ability to establish viable population in shaded environments is 280 associated with low root diameter and high SRL. The increase of light EiV for trees and shrubs was related 281 with an increase of tissue density and a decrease of RNC.

282 Regarding soil properties, only the soil texture EiV was strongly related to root traits, with a substantial 283 effect on SRL, RTD and RNC both at the level of the whole dataset and for most growth forms. Species 284 from more sandy soils showed high SRL, RNC and low RTD in comparison with species from more loamy 285 soils. Additionally, the root diameter of forbs was positively related with soil texture EiV. At the level of 286 plant growth forms, the organic matter EiV was positively related with RTD for forbs only; and the pH EiV 287 was negatively related with SRL of trees, shrubs and forbs and positively related with RNC of trees and 288 shrubs (Fig. 3).

289 Finally, the multivariate analysis of correlation (pCCA based on a 68 species subsample) demonstrated 290 further a strong link between EiV values and root traits along a trade-off between species building thin, 291 light roots with high SRL and these presenting coarse and dense roots (Fig. 4). This functional trade-off 292 was related to an EiV axis separating denser (i.e. shaded) and more fertile habitats (nutrient-rich, humid 293 soils, although with low $\mathrm{pH}$ ), from more open habitats with drier and poorer soil conditions.

\section{Discussion}

295 Our analyses demonstrate that species ecological indicator values, together with phylogenetic information, 296 are valuable predictors of plant below-ground strategies. They shed light on several environmental 297 parameters strongly connected to fine-root trait variation: nutrient and water availability and soil texture 298 below-ground, as well as light and temperature above-ground. As hypothesised, ecological indicators 299 related to nutrient availability and soil texture were the most strongly related to fine-root trait values, 300 highlighting the importance of these traits for species adaptation to the availability of soil resources. 301 Importantly, species growth forms had a strong impact on the relationships between traits and EiV, with 302 woody species sometimes displaying opposite responses to herbaceous species, especially for resource303 related ecological indicators. All four traits, root diameter, SRL, RTD and RNC, considered as major traits

304 supporting the "fast-slow" root economic spectrum (together with root lifespan and root respiration rate; 305 Reich, 2014; Roumet et al., 2016) and/or the trade-off between building thin roots or thick roots relying on 306 mycorrhiza (Kong et al., 2019; McCormack \& Iversen, 2019), were (at least partly) differently related to 307 species habitat in terms of climate, nutrient availability and other soil properties. This finding of multiple 
308 determinants of fine-root trait global distribution implies that root trait values cannot be simply represented

309 by one single strong environmental axis.

310 Relevance of accounting for phylogenetic relatedness

311 This work confirms that root functional traits carry a strong phylogenetic signal (Comas et al., 2012), 312 although the strength of this signal for all four traits differed between this and other datasets (e.g. Freschet 313 et al., 2017; Valverde-Barrantes et al., 2017; Ma et al., 2018) following distinct representations of the 314 global species set and different entities of root studied. This substantial phylogenetic signal was generally 315 consistent with ancient history of root-mycorrhiza coevolution (Ma et al., 2018) and historical evolution of 316 tissue organisation and development (Comas, Callahan, \& Midford, 2014), such as the capacity of dicot 317 species to perform secondary growth in contrast to monocots, or the tendency of Fabaceae to accumulate 318 root $\mathrm{N}$ potentially relating to their ability to associate with $\mathrm{N}_{2}$-fixing symbionts (Freschet et al., 2017).

319 Root traits vary according to ecological indicators values

320 Fine-root diameter is a major determinant of plant species resource use strategies (Eissenstat, 1992; Ma et 321 al., 2018; McCormack et al., 2017). Large fine-root diameters are generally associated with slow resource 322 use (Eissenstat, 1992; Roumet et al., 2016), high storage and water transport capacities (Fort et al., 2017; 323 Hernández, Vilagrosa, Pausas, \& Bellot, 2010) and high dependence on mycorrhiza to acquire soil 324 resources (Kong et al., 2019; McCormack \& Iversen, 2019). Despite such evidence of the role of fine-root 325 diameter in species strategies, our analysis did not reveal strong links between fine-root diameter and 326 species ecological indicators values (except for light). This is potentially due to our accounting of fine-root 327 diameter strong phylogenetic signal, which may overlap with the ecological information carried by this 328 trait. Across all plant growth forms, root diameter only related with light EiV, with shade tolerant species 329 displaying thinner root diameter. This relation could be related to a change in carbon economy along light 330 availability gradients, i.e. fine-root diameter generally associated with high SRL (Ma et al., 2018) could be 331 advantageous within shaded environments where carbon supply is limiting (Vernay, 2017). The large 332 representation of short plants among shade tolerant species (mainly grasses, forbs and shrubs) could also 333 contribute to the observed link between species light exigency and root diameter.

334 Specific root length is strongly related with mean root diameter following a general nonlinear asymmetric 335 relation (Ma et al., 2018). However, our results suggest that across all plant growth forms SRL is more 336 strongly related to species adaptation to a range of environmental gradients than fine-root diameter (see 337 also Valverde-Barrantes et al., 2017). The positive relationship between SRL and the nutrient EiV 338 highlights that having high SRL values is one of the key for plants to succeed in nutrient-rich 339 environments. Indeed, high SRL may provide higher competitive ability, at least among grassland species 340 (Mommer et al., 2011). The strong negative relationship observed between the temperature EiV and SRL 
341 strengthens the patterns observed with global climatic variables (Freschet et al., 2017; Valverde-Barrantes 342 et al., 2017) or at finer scales, such as in studies comparing root traits of tree species from different latitudes 343 (Ostonen et al., 2007). High SRL is further associated with faster root elongation rates and higher potential 344 to proliferate in nutrient patches (Eissenstat, 1992; Eissenstat, Kucharski, Zadworny, Adams, \& Koide, 345 2015; Hodge, 2006). These characteristics should be particularly useful to acquire resources in colder 346 environments where strong seasonality and soil freezing could lead to heterogeneous and intermittent soil 347 microbial activity and nutrient availability (Bardgett, Bowman, Kaufmann, \& Schmidt, 2005; Chen, Zeng, 348 Eissenstat, \& Guo, 2013).

349 Specific root length is also strongly and positively related to soil texture EiV, that is, it decreases as soil 350 texture becomes dominated by silt and clay. Soil texture is one of the major driver of bulk soil density, and 351 water, nutrient and air contents and movement in soil (Alameda \& Villar, 2012; Arvidsson, 1998; Pabin, 352 Lipiec, Wlodek, Biskupski, \& Kaus, 1998). All these parameters are known to have complex influences on 353 root growth and root traits. Bulk density for instance, which is negatively related to soil clay and silt 354 content, is known to increase the resistance to root penetration and limit root growth (Dexter, 2004; Jones, 355 1983); and species with thicker fine-roots, and therefore lower SRL, are generally better adapted to denser 356 soils because of their higher soil penetration strengths (Bengough, McKenzie, Hallett, \& Valentine, 2011; 357 Materechera, Alston, Kirby, \& Dexter, 1992). The negative relation between RTD and the soil texture EiV 358 also strengthens the idea that dense roots with a high investment in structural tissues, and therefore of lower 359 SRL, are beneficial in soil with high content of clay and silt (Freschet et al., 2017) where even low soil 360 penetration resistance and bulk density may limit root growth (Pabin et al., 1998).

361 Across all species, RTD is with RNC one of the two traits that relate to atmospheric humidity EiV. Species 362 adaptation to atmospheric humidity is linked to their management of water vapour pressure deficit (Kupper 363 et al., 2017; Sellin et al., 2017). At the intraspecific level, changes in vapour deficit affect hydraulic 364 properties of roots and leaves (Claverie, Schoppach, \& Sadok, 2016). The higher RTD of species from high 365 atmospheric humidity may be related to higher investment in root stele relative to cortex tissues (Kong et 366 al., 2016), in order to facilitate water fluxes across plant organs (Oksanen et al., 2018). The positive 367 relationship between RNC and the atmospheric humidity EiV could be related to a stronger investment in 368 root metabolic activity in conditions where nutrients are less mobile due to limited water flux from the soil 369 to the atmosphere (Oksanen et al., 2018).

370 Root tissue density and nitrogen concentration are also strongly but negatively related to water availability 371 EiV, indicating that species characterised by low RTD and RNC are more represented in high water 372 availability environments. More specifically, wetland species display the lowest RTD values, which can be 
373 related to their capacity to produce aerenchyma in order to limit tissues hypoxia in waterlogged conditions 374 (Justin \& Armstrong, 1987).

375 In support of our first hypothesis, ecological indicators of soil resource availability were strongly related to 376 fine-root trait values, with water and nutrient EiV showing a strong influence on SRL, RTD and RNC. 377 Nonetheless, they were not the only environmental variables connected to fine-root trait variation. Light 378 EiV appeared also important for fine-root diameter and SRL. All three climate EiV, temperature, 379 continentality and atmospheric humidity, were related to at least one of the four traits studied and, although 380 classical soil EiV such as $\mathrm{pH}$ and organic matter content appeared poorly linked to fine-root trait values, 381 soil texture showed a strong link with SRL, RTD and RNC.

382 Largely consistent with the univariate analyses, our multivariate approach shows that the trait spectrum 383 separating species with high SRL and RNC but low RTD (and also low root diameter) and species with the 384 opposite characteristics relates to an axis separating species from nutrient-rich, humid, low soil $\mathrm{pH}$ and 385 shaded habitats to those with the opposite ecological preferences. These results, essentially derived from 386 data on herbaceous species, strengthen the idea that fast use of soil resources through low tissue density and 387 thin elongated roots (and therefore short root lifespan; McCormack et al., 2012; Ma et al., 2018) and high 388 nitrogen concentration (associated to high respiration rates; Reich et al., 2008) is an efficient way to avoid 389 being suppressed by competitors in nutrient-rich habitats (Fort, Cruz, \& Jouany, 2014; Grime, 1977; Reich, 390 2014). In contrast, the opposite root trait syndrome (low RNC, SRL and high RTD) would allow plants to 391 strive in nutrient-poor conditions where fast resource use is less suitable. However, more work is needed to 392 assess the generality of this trend across woody species. Additionally, future analyses would strongly 393 benefit from the inclusion of data from a wider range of environmental conditions (providing that future 394 studies increasingly consider extreme environmental conditions) and a wider range of species, so as to 395 extend our analysis to better capture non-linear patterns of trait-environment relationships.

\section{Opposite patterns between woody and herbaceous species}

397 Beyond the general patterns observed across all species, growth forms had a strong impact on the 398 relationships between traits and ecological indicators, with woody species sometimes displaying opposite 399 responses to herbaceous species, especially for resource-related EiV. Most particularly, in nutrient-rich 400 environments, woody species tended to rely on high-diameter, low SRL and low RNC roots, which 401 contrasted strongly with herbaceous species, especially grasses. Plant root systems have multiple ways to 402 deal with low soil nutrient availability (e.g. increasing SRL, Bauhus \& Messier, 1999; root hair length and 403 density, Yang et al., 2015; mycorrhizal association and cluster roots, Lambers, Raven, Shaver, \& Smith, 404 2008). In this context, our results might reflect a higher reliance of woody species on mycorrhizal 405 association (McCormack \& Iversen, 2019) in nutrient-rich conditions, whereas grasses would typically 
406 adopt high SRL roots, with higher metabolic activities. Grass species also showed lower RNC and RTD in 407 high water availability environments, whereas the contrary was true for woody species, suggesting different 408 adaptations of grasses and woody species to high water conditions, including higher reliance on 409 aerenchyma for grasses. Overall, these results suggest that plant species adaptation to their environment 410 may depend on a larger set of plant characteristics linked to growth forms (e.g., among many other 411 potential traits, size, lifespan, woodiness) that set different constraints on plants in view to overcome the 412 same stresses and limitations. Such results limit our ability to define simple, widely applicable patterns of 413 trait-environment relationships and illustrate how different plant community assembly processes may apply 414 to contrasting sets of species.

\section{Conclusion}

416 Our results demonstrate that ecological indicators describing species habitat have the potential to explain 417 trait variation among a large range of species from various families and environments. Since species EiV 418 are estimated across entire populations of individuals occurring across a range of environments, they can be 419 meaningfully related to trait data coming from heterogeneous databases where traits have been measured in 420 a range of plant growth conditions. While EiV do not allow to precisely predict species trait values due to 421 their categorical nature they are nonetheless useful to explain trait variations among species and habitats 422 and help improve our knowledge about root trait ecological significance. In this context, the development 423 of homogenised EiV bridging locally-based systems is further needed to improve the value of ecological

424 indicators over large scales. Here, this original approach showed that fine-root trait variations were related

425 to species adaptation to a range of environmental parameters including resource availability, climate and

426 soil texture. Traits supporting the concept of "fast-slow" root economics spectrum were strongly related to 427 soil nutrient availability. However, such relations differed strongly between woody and herbaceous species. 428 Moreover, our results showed a range of other covariations between fine-root traits and environmental 429 parameters, indicating that the global distribution of fine-root traits cannot be simply synthetized by one 430 single axis of trait-environment covariation.

\section{Acknowledgments}

432 We would like to thank Catherine Roumet and Katherine Urban-Mead for their contribution to building the 433 Rhizopolis database, and Caroline Tucker for her help in incorporating phylogeny into this study. We also 434 thank the editor and two anonymous reviewers whose constructive comments greatly improved the quality 435 of this work.

\section{Authors' contributions}

437 FF and GTF conceived the ideas, designed the methodology, analysed the data and wrote the manuscript. 


\section{Data Availability Statement}

439 All data used in the preparation of this manuscript, i.e., Rhizopolis database (Freschet et al., 2017; available 440 as part of the Fine-Root Ecology database, http://roots.ornl.gov), Baseflor database (Julve, 2015; 441 http://philippe.julve.pagesperso-orange.fr/catminat.htm) and the phylogenetic tree (Zanne et al., 2014; 442 http://dx.doi.org/10.5061/dryad.63q27), are freely accessible. 
444 Alameda, D., \& Villar, R. (2012). Linking root traits to plant physiology and growth in Fraxinus 445 angustifolia Vahl. seedlings under soil compaction conditions. Environmental and Experimental $446 \quad$ Botany, 79, 49-57. doi:10.1016/j.envexpbot.2012.01.004

447 APG III. (2016). An update of the Angiosperm Phylogeny Group classification for the orders and families 448 of flowering plants: APG IV. Botanical Journal of the Linnean Society, 181(1), 1-20. doi:10.1111/boj.12385

450 Arvidsson, J. (1998). Influence of soil texture and organic matter content on bulk density, air content, 451 compression index and crop yield in field and laboratory compression experiments. Soil and Tillage 452 Research, 49(1-2), 159-170. doi:10.1016/S0167-1987(98)00164-0

453 Bardgett, R., Bowman, W., Kaufmann, R., \& Schmidt, S. (2005). A temporal approach to linking 454 aboveground and belowground ecology. Trends in Ecology \& Evolution, 20(11), 634-641. 455 doi:10.1016/j.tree.2005.08.005

456 Bartelheimer, M., \& Poschlod, P. (2016). Functional characterizations of Ellenberg indicator values - a 457 review on ecophysiological determinants. Functional Ecology, 30(4), 506-516. doi:10.1111/1365458 2435.12531

459 Bartoń, K. (2016). Model selection and model averaging based on information criteria (AICc and alike). 460 Retrieved from https://cran.r-project.org/package=MuMIn 461 Bates, D., Mächler, M., Bolker, B., \& Walker, S. (2015). Fitting Linear Mixed-Effects Models Using lme4. Journal of Statistical Software, 67(1). doi:10.18637/jss.v067.i01

463 Bauhus, J., \& Messier, C. (1999). Soil exploitation strategies of fine roots in different tree species of the 464 southern boreal forest of eastern Canada. Canadian Journal of Forest Research, 29, 260-273.

465 Bengough, A. G. G., McKenzie, B. M. M., Hallett, P. D. D., \& Valentine, T. A. a. (2011). Root elongation, 466 water stress, and mechanical impedance: a review of limiting stresses and beneficial root tip traits. 467 Journal of Experimental Botany, 62(1), 59-68. doi:10.1093/jxb/erq350

468 Cavender-Bares, J., Kozak, K. H., Fine, P. V. a, \& Kembel, S. W. (2009). The merging of community 469 ecology and phylogenetic biology. Ecology Letters, 12(7), 693-715. doi:10.1111/j.1461$470 \quad$ 0248.2009.01314.x

471 Chamberlain, S. A., Hovick, S. M., Dibble, C. J., Rasmussen, N. L., Van Allen, B. G., Maitner, B. S., ... Whitney, K. D. (2012). Does phylogeny matter? Assessing the impact of phylogenetic information in 
474 Chen, W., Zeng, H., Eissenstat, D. M., \& Guo, D. (2013). Variation of first-order root traits across climatic 475 gradients and evolutionary trends in geological time. Global Ecology and Biogeography, 22(7), 846476 856. doi:10.1111/geb.12048

477 Claverie, E., Schoppach, R., \& Sadok, W. (2016). Nighttime evaporative demand induces plasticity in leaf $478 \quad$ and root hydraulic traits. Physiologia Plantarum, 158(4), 402-413. doi:10.1111/ppl.12474

479 Comas, L. H., Mueller, K. E., Taylor, L. L., Midford, P. E., Callahan, H. S., \& Beerling, D. J. (2012). 480 Evolutionary Patterns and Biogeochemical Significance of Angiosperm Root Traits. International Journal of Plant Sciences, 173(6), 584-595. doi:10.1086/665823

482 Comas, Louise H., Callahan, H. S., \& Midford, P. E. (2014). Patterns in root traits of woody species 483 hosting arbuscular and ectomycorrhizas: implications for the evolution of belowground strategies. Ecology and Evolution, 4(15), 2979-2990. doi:10.1002/ece3.1147

485 Conti, L., de Bello, F., Lepš, J., Acosta, A. T. R., \& Carboni, M. (2017). Environmental gradients and 486 micro-heterogeneity shape fine scale plant community assembly on coastal dunes. Journal of 487 Vegetation Science, 38(1), 42-49. doi:10.1111/jvs. 12533

488 Craine, J. M., Froehle, J., Tilman, D. G., Wedin, D. A., \& Chapin, III, F. S. (2001). The relationships 489 among root and leaf traits of 76 grassland species and relative abundance along fertility and 490 disturbance gradients. Oikos, 93(2), 274-285. doi:10.1034/j.1600-0706.2001.930210.x

491 Dexter, a R. (2004). Soil physical quality Part I. Theory, effects of soil texture, density, and organic mailer, 492 and effects on root growth. Geoderma, 120, 201-214. doi:10.1016/j.geodermaa.2003.09.005

493 Diekmann, M. (2003). Species indicator values as an important tool in applied plant ecology - a review. 494 Basic and Applied Ecology, 4(6), 493-506. doi:10.1078/1439-1791-00185

495 Eissenstat, D. M. (1992). Costs and benefits of constructing roots of small diameter. Journal of Plant 496 Nutrition, 15(6-7), 763-782. doi:10.1080/01904169209364361

497 Eissenstat, D. M., Kucharski, J. M., Zadworny, M., Adams, T. S., \& Koide, R. T. (2015). Linking root traits 498 to nutrient foraging in arbuscular mycorrhizal trees in a temperate forest. New Phytologist, 208(1), 114-124. doi:10.1111/nph.13451

500 Ellenberg, H., Weber, H. E., Düll, R., Wirth, V., Werner, W., \& Paulißen, D. (1991). Zeigerwerte von 501 Pflanzen in Mitteleuropa. Scripta Geobotanica, 18, 9-160.

502 Forde, B., \& Lorenzo, H. (2001). The nutritional control of root development. Plant and Soil, $232,51-68$. 
503 Fort, F., Cruz, P., \& Jouany, C. (2014). Hierarchy of root functional trait values and plasticity drive early504 stage competition for water and phosphorus among grasses. Functional Ecology, 28(4), 1030-1040. doi:10.1111/1365-2435.12217

506 Fort, F., Cruz, P., Lecloux, E., Bittencourt de Oliveira, L., Stroia, C., Theau, J.-P. P., \& Jouany, C. (2016).

507 Grassland root functional parameters vary according to a community-level resource acquisition-

508 conservation trade-off. Journal of Vegetation Science, 27(4), 749-758. doi:10.1111/jvs.12405

509 Fort, F., Jouany, C., \& Cruz, P. (2015). Hierarchical traits distances explain grassland Fabaceae species '

510 ecological niches distances. Frontiers in Plant Science, 6(February), 1-11.

511 doi:10.3389/fpls.2015.00063

512 Fort, F., Volaire, F., Guilioni, L., Barkaoui, K., Navas, M.-L., \& Roumet, C. (2017). Root traits are related

513 to plant water-use among rangeland Mediterranean species. Functional Ecology, 31(9), 1700-1709.

514 doi:10.1111/1365-2435.12888

515 Freschet, G. T., Cornelissen, J. H. C., van Logtestijn, R. S. P., \& Aerts, R. (2010). Evidence of the 'plant 516 economics spectrum' in a subarctic flora. Journal of Ecology, 98(2), 362-373. doi:10.1111/j.1365$517 \quad 2745.2009 .01615 . x$

518 Freschet, G. T., \& Roumet, C. (2017). Sampling roots to capture plant and soil functions. Functional $519 \quad$ Ecology, 31(8), 1506-1518. doi:10.1111/1365-2435.12883

520 Freschet, G. T., Valverde-Barrantes, O. J., Tucker, C. M., Craine, J. M., McCormack, L. M., Violle, C., ... 521 Roumet, C. (2017). Climate, soil and plant functional types as drivers of global fine-root trait variation. Journal of Ecology, 38(1), 42-49. doi:10.1111/1365-2745.12769

523 Garnier, E., Stahl, U., Laporte, M.-A., Kattge, J., Mougenot, I., Kühn, I., ... Klotz, S. (2016). Towards a 524 thesaurus of plant characteristics: an ecological contribution. Journal of Ecology, (i), 1-12. 525 doi:10.1111/1365-2745.12698

526 Grime, J. P. (1977). Evidence for the existence of three primary strategies in plants and its relevance to 527 ecological and evolutionary theory. American Naturalist, 111(982), 1169-1194. doi:10.1086/283244

528 Herben, T., Tackenberg, O., \& Klimešová, J. (2016). Reproduction by seed and clonality in plants: 529 correlated syndromes or independent strategies? Journal of Ecology, 104(6), 1696-1706. doi:10.1111/1365-2745.12646

531 Hernández, E. I., Vilagrosa, A., Pausas, J. G., \& Bellot, J. (2010). Morphological traits and water use strategies in seedlings of Mediterranean coexisting species. Plant Ecology, 207(2), 233-244. doi:10.1007/s11258-009-9668-2 
534 Hill, J. O., Simpson, R. J., Moore, A. D., \& Chapman, D. F. (2006). Morphology and response of roots of 535 pasture species to phosphorus and nitrogen nutrition. Plant and Soil, 286(1-2), 7-19. doi:10.1007/s11104-006-0014-3

537 Hodge, A. (2006). Plastic plants and patchy soils. Journal of Experimental Botany, 57(2), 401-11.

538 doi: $10.1093 / \mathrm{j} \times \mathrm{b} / \mathrm{eri} 280$

539 Hutchinson, G. E. (1957). The multivariate niche. In Cold Spring Harbor Symposia on Quantitative $540 \quad$ Biology (pp. 415-421).

541 Iversen, C. M., McCormack, M. L., Powell, A. S., Blackwood, C. B., Freschet, G. T., Kattge, J., ... Violle, 542 C. (2017). A global Fine-Root Ecology Database to address below-ground challenges in plant $543 \quad$ ecology. New Phytologist. doi:10.1111/nph.14486

544 Jager, M. M., Richardson, S. J., Bellingham, P. J., Clearwater, M. J., \& Laughlin, D. C. (2015). Soil 545 fertility induces coordinated responses of multiple independent functional traits. Journal of Ecology, $546 \quad$ 103(2), 374-385. doi:10.1111/1365-2745.12366

547 Janse-Ten Klooster, S. H., Thomas, E. J. P., \& Sterck, F. J. (2007). Explaining interspecific differences in 548 sapling growth and shade tolerance in temperate forests. Journal of Ecology, 95(6), 1250-1260. 549 doi:10.1111/j.1365-2745.2007.01299.x

550 Johnson, J. B., \& Omland, K. S. (2004). Model selection in ecology and evolution. Trends in Ecology \& $551 \quad$ Evolution, $19(2), 101-108$. doi:10.1016/j.tree.2003.10.013

552 Jones, C. A. (1983). Effect of Soil Texture on Critical Bulk Densities for Root Growth1. Soil Science 553 Society of America Journal, 47(6), 1208. doi:10.2136/sssaj1983.03615995004700060029x

554 Julve, P. (2009). La valence écologique des plantes et son utilisation en bioindication. In Les indicateurs 555 des milieux tourbeux et zones humides associées. Pau.

556 Julve, P. (2015). Baseflor. Index botanique, écologique et chorologique de la flore de France. Retrieved 557 January 4, 2016, from http://philippe.julve.pagesperso-orange.fr/catminat.htm

558 Justin, S. H. F. W., \& Armstrong, W. (1987). The Anatomical Characteristics of Roots and Plant Response 559 to Soil Flooding. New Phytologist, 106(3), 465-495.

560 Keddy, P. a. (1992). Assembly and response rules: two goals for predictive community ecology. Journal of $561 \quad$ Vegetation Science, 3(2), 157-164. doi:10.2307/3235676

562 Kong, D., Wang, J., Wu, H., Valverde-Barrantes, OJ. Wang, R., Zeng, H., Kardol, P., ... Feng, Y. (2019). Nonlinearity of root trait relationships and the root economics spectrum. Nature Communications, 10, 
565 Kong, D., Wang, J., Zeng, H., Liu, M., Miao, Y., Wu, H., \& Kardol, P. (2016). The nutrient absorption566 transportation hypothesis: optimizing structural traits in absorptive roots. New Phytologist, 213, 1569$567 \quad 1572$.

568 Kramer-Walter, K. R., Bellingham, P. J., Millar, T. R., Smissen, R. D., Richardson, S. J., \& Laughlin, D. C. 569 (2016). Root traits are multidimensional: specific root length is independent from root tissue density $570 \quad$ and the plant economic spectrum. Journal of Ecology, 104(5), 1299-1310. doi:10.1111/13652745.12562

572 Kupper, P., Rohula, G., Inno, L., Ostonen, I., Sellin, A., \& Sõber, A. (2017). Impact of high daytime air 573 humidity on nutrient uptake and night-time water flux in silver birch, a boreal forest tree species. Regional Environmental Change, 17(7), 2149-2157. doi:10.1007/s10113-016-1092-2

575 Lortie, C. J., Brooker, R. W., Choler, P., Kikvidze, Z., Michalet, R., Pugnaire, F. I., \& Callaway, R. M.

576 (2004). Rethinking plant community theory. Oikos, 107(2), 433-438. doi:10.1111/j.0030$577 \quad 1299.2004 .13250 . x$

578 Ma, Z., Guo, D., Xu, X., Lu, M., Bardgett, R. D., Eissenstat, D. M., ... Hedin, L. O. (2018). Evolutionary 579 history resolves global organization of root functional traits. Nature, 555(7694), 94-97. doi:10.1038/nature25783

581 Maire, V., Wright, I. J., Prentice, I. C., Batjes, N. H., Bhaskar, R., van Bodegom, P. M., ... Santiago, L. S. 582 (2015). Global effects of soil and climate on leaf photosynthetic traits and rates. Global Ecology and 583 Biogeography, 24(6), 706-717. doi:10.1111/geb.12296

584 Materechera, S. A. A., Alston, A. M. M., Kirby, J. M. M., \& Dexter, A. R. R. (1992). Influence of root 585 diameter on the penetration of seminal roots into a compacted subsoil. Plant and Soil, 144(2), 297586 303. doi:10.1007/BF00012888

587 McCormack, L. M., Adams, T. S., Smithwick, E. A. H., \& Eissenstat, D. M. (2012). Predicting fine root 588 lifespan from plant functional traits in temperate trees. New Phytologist, 195(4), 823-31.

589 doi:10.1111/j.1469-8137.2012.04198.x

590 McCormack, M. L., Guo, D., Iversen, C. M., Chen, W., Eissenstat, D. M., Fernandez, C. W., ... Zanne, A. 591 (2017). Building a better foundation: improving root-trait measurements to understand and model 592 plant and ecosystem processes. New Phytologist, 215(1), 27-37. doi:10.1111/nph.14459

593 McCormack, M. L., \& Iversen, C. M. (2019). Physical and Functional Constraints on Viable Belowground Acquisition Strategies. Frontiers in Plant Science, 10(October), 1-12. doi:10.3389/fpls.2019.01215 

functional traits. Trends in Ecology \& Evolution, 21(4), 178-85. doi:10.1016/j.tree.2006.02.002

597 Moles, A. T., Perkins, S. E., Laffan, S. W., Flores-Moreno, H., Awasthy, M., Tindall, M. L., ... Bonser, S. 598 P. (2014). Which is a better predictor of plant traits: temperature or precipitation? Journal of $599 \quad$ Vegetation Science, 25(5), 1167-1180. doi:10.1111/jvs.12190

600 Mommer, L., Visser, E. J. W., Ruijven, J., Caluwe, H., Pierik, R., \& Kroon, H. (2011). Contrasting root 601 behaviour in two grass species: a test of functionality in dynamic heterogeneous conditions. Plant and Soil, 344(1-2), 347-360. doi:10.1007/s11104-011-0752-8

603 Münkemüller, T., Lavergne, S., Bzeznik, B., Dray, S., Jombart, T., Schiffers, K., \& Thuiller, W. (2012).

$604 \quad$ How to measure and test phylogenetic signal. Methods in Ecology and Evolution, 3(4), 743-756.

605 doi:10.1111/j.2041-210X.2012.00196.x

606 Nakagawa, S., \& Schielzeth, H. (2013). A general and simple method for obtaining R 2 from generalized 607 linear mixed-effects models. Methods in Ecology and Evolution, 4(2), 133-142. doi:10.1111/j.2041608 210x.2012.00261.x

609 Niinemets, Ü. (2010). A review of light interception in plant stands from leaf to canopy in different plant 610 functional types and in species with varying shade tolerance. Ecological Research, 25(4), 693-714. doi:10.1007/s11284-010-0712-4

612 Oksanen, E., Lihavainen, J., Keinänen, M., Keski-Saari, S., Kontunen-Soppela, S., Sellin, A., \& Sõber, A. 613 (2018). Northern Forest Trees Under Increasing Atmospheric Humidity. In Progress in Botany (pp. 614 1-23). doi:10.1007/124_2017_15

615 Ordoñez, J. C., van Bodegom, P. M., Witte, J.-P. M., Wright, I. J., Reich, P. B., \& Aerts, R. (2009). A 616 global study of relationships between leaf traits, climate and soil measures of nutrient fertility. Global 617 Ecology and Biogeography, 18(2), 137-149. doi:10.1111/j.1466-8238.2008.00441.x

618 Ostonen, I., Püttsepp, Ü., Biel, C., Alberton, O., Bakker, M. R., Lõhmus, K., ... Brunner, I. (2007). Specific 619 root length as an indicator of environmental change. Plant Biosystems - An International Journal 620 Dealing with All Aspects of Plant Biology, 141(3), 426-442. doi:10.1080/11263500701626069

621 Pabin, J., Lipiec, J., Wlodek, S., Biskupski, A., \& Kaus, A. (1998). Critical soil bulk density and strength 622 for pea seedling root growth as related to other soil factors. Soil \& Tillage Research, 46(3-4), 203623 208. doi:10.1016/S0167-1987(98)00098-1

624 Pinheiro, J., Bates, D., DebRoy, S., Sarkar, D., \& Team, R. C. (2016). nlme: Linear and Nonlinear Mixed 625 Effects Models. Retrieved from http://cran.r-project.org/package=nlme.

This article is protected by copyright. All rights reserved 
626 Prieto, I., Roumet, C., Cardinael, R., Dupraz, C., Jourdan, C., Kim, J. H., ... Stokes, A. (2015). Root

627 functional parameters along a land-use gradient: evidence of a community-level economics spectrum.

$628 \quad$ Journal of Ecology, 103(2), 361-373. doi:10.1111/1365-2745.12351

629 Qian, H., \& Jin, Y. (2016). An updated megaphylogeny of plants, a tool for generating plant phylogenies

630 and an analysis of phylogenetic community structure. Journal of Plant Ecology, 9(2), 233-239.

631 doi:10.1093/jpe/rtv047

632 Reich, P. B. (2014). The world-wide ' fast - slow ' plant economics spectrum : a traits manifesto. Journal of Ecology, 102, 275-301. doi:10.1111/1365-2745.12211

634 Reich, P. B., Tjoelker, M. G., Pregitzer, K. S., Wright, I. J., Oleksyn, J., \& Machado, J. L. (2008). Scaling 635 of respiration to nitrogen in leaves, stems and roots of higher land plants. Ecology Letters, 11(8), 793636 801. doi:10.1111/j.1461-0248.2008.01185.x

637 Revell, L. J. (2012). phytools: an R package for phylogenetic comparative biology (and other things).

638 Methods in Ecology and Evolution, 3(2), 217-223. doi:10.1111/j.2041-210X.2011.00169.x

639 Roumet, C., Birouste, M., Picon-Cochard, C., Ghestem, M., Osman, N., Vrignon-Brenas, S., ... Stokes, A. 640 (2016). Root structure-function relationships in 74 species: Evidence of a root economics spectrum 641 related to carbon economy. New Phytologist, 210(3), 815-826. doi:10.1111/nph.13828

642 Ryser, P. (1996). The Importance of Tissue Density for Growth and Life Span of Leaves and Roots: A 643 Comparison of Five Ecologically Contrasting Grasses. Functional Ecology, 10(6), 717. 644 doi: $10.2307 / 2390506$

645 Sellin, A., Alber, M., Keinänen, M., Kupper, P., Lihavainen, J., Lõhmus, K., ... Tullus, A. (2017). Growth 646 of northern deciduous trees under increasing atmospheric humidity: possible mechanisms behind the 647 growth retardation. Regional Environmental Change, 17(7), 2135-2148. doi:10.1007/s10113-016$648 \quad 1042-\mathrm{z}$

649 Shipley, B., Belluau, M., Kühn, I., Soudzilovskaia, N. A., Bahn, M., Penuelas, J., ... Poschlod, P. (2017). 650 Predicting habitat affinities of plant species using commonly measured functional traits. Journal of 651 Vegetation Science, 28(5), 1082-1095. doi:10.1111/jvs.12554

652 Silvertown, J., Dodd, M., Gowing, D., Lawson, C., \& McConway, K. (2006). PHYLOGENY AND THE 653 HIERARCHICAL ORGANIZATION OF PLANT DIVERSITY. Ecology, 87(sp7), S39-S49. 654 doi:10.1890/0012-9658(2006)87[39:PATHOO]2.0.CO;2

655 Stone, G. N., Nee, S., \& Felsenstein, J. (2011). Controlling for non-independence in comparative analysis 656 of patterns across populations within species. Philosophical Transactions of the Royal Society B:

This article is protected by copyright. All rights reserved 
658 Valverde-Barrantes, O. J., Freschet, G. T., Roumet, C., \& Blackwood, C. B. (2017). A worldview of root 659 traits: the influence of ancestry, growth form, climate and mycorrhizal association on the functional 660 trait variation of fine-root tissues in seed plants. New Phytologist, 215(4), 1562-1573.

661 doi:10.1111/nph.14571

662 Vernay, A. (2017). De la complexité fonctionnelle et écophysiologique des ressources lumière, azote et eau 663 dans le réseau précoce d'interactions entre le jeune chêne et deux poacées : conséquences pour la régénération des chênaies tempérées. Université de Clermont Auvergne.

665 Violle, C., Navas, M. L., Vile, D., Kazakou, E., Fortunel, C., Hummel, I., \& Garnier, E. (2007, May). Let 666 the concept of trait be functional! Oikos. doi:10.1111/j.2007.0030-1299.15559.x

667 Vojtkó, A. E., Freitag, M., Bricca, A., Martello, F., Compañ, J. M., Küttim, M., ... Götzenberger, L. 668 (2017). Clonal vs leaf-height-seed (LHS) traits: which are filtered more strongly across habitats? 669 Folia Geobotanica, 52(3-4), 269-281. doi:10.1007/s12224-017-9292-1

670 Weemstra, M., Mommer, L., Visser, E. J. W., van Ruijven, J., Kuyper, T. W., Mohren, G. M. J., \& Sterck, 671 F. J. (2016). Towards a multidimensional root trait framework: a tree root review. New Phytologist, 672 211(4), 1159-1169. doi:10.1111/nph.14003

673 Westoby, M. (1998). A leaf-height-seed ( LHS ) plant ecology strategy scheme. Plant and Soil, 199, $213-$ 674 227.

675 Yang, Z., Culvenor, R. a., Haling, R. E., Stefanski, A., Ryan, M. H., Sandral, G. a., .. Simpson, R. J. 676 (2015). Variation in root traits associated with nutrient foraging among temperate pasture legumes 677 and grasses. Grass and Forage Science, (April), n/a-n/a. doi:10.1111/gfs.12199

678 Zanne, A. E., Tank, D. C., Cornwell, W. K., Eastman, J. M., Smith, S. A., FitzJohn, R. G., ... Beaulieu, J. 679 M. (2014). Three keys to the radiation of angiosperms into freezing environments. Nature, 506(7486), 89-92. doi:10.1038/nature12872 
Table 1. Description of dataset main characteristics for each trait after crossing all three databases.

\begin{tabular}{|c|c|c|c|c|c|c|c|c|c|}
\hline \multirow[b]{2}{*}{ Traits } & \multirow[b]{2}{*}{ Min } & \multirow[b]{2}{*}{ Mean } & \multirow[b]{2}{*}{ Max } & \multirow[b]{2}{*}{$\mathrm{cV}$} & \multirow{2}{*}{$\begin{array}{c}\text { Number } \\
\text { of } \\
\text { datasets }\end{array}$} & \multirow{2}{*}{$\begin{array}{c}\text { Number } \\
\text { of } \\
\text { families }\end{array}$} & \multirow{2}{*}{$\begin{array}{c}\text { Number } \\
\text { of } \\
\text { species }\end{array}$} & \multicolumn{2}{|c|}{ Phylogenetic signal } \\
\hline & & & & & & & & Lambda & p-value \\
\hline $\mathrm{D}(\mathrm{mm})$ & 0.14 & 0.30 & 0.55 & 0.29 & 19 & 44 & 182 & 0.80 & $<0.001$ \\
\hline $\operatorname{SRL}\left(\mathrm{m} \mathrm{g}^{-1}\right)$ & 6.17 & 104.8 & 936.4 & 1.07 & 24 & 49 & 218 & 0.84 & $<0.001$ \\
\hline $\operatorname{RTD}\left(\mathrm{g} \mathrm{cm}^{-3}\right)$ & 0.04 & 0.29 & 1.18 & 0.69 & 16 & 44 & 172 & 0.76 & $<0.001$ \\
\hline $\mathrm{RNC}\left(\mathrm{mg} \mathrm{kg}^{-}\right.$ & 3.15 & 12.36 & 42.2 & 0.48 & 18 & 33 & 144 & & \\
\hline$\left.{ }^{1}\right)$ & & & & & & & & 0.59 & $<0.001$ \\
\hline
\end{tabular}




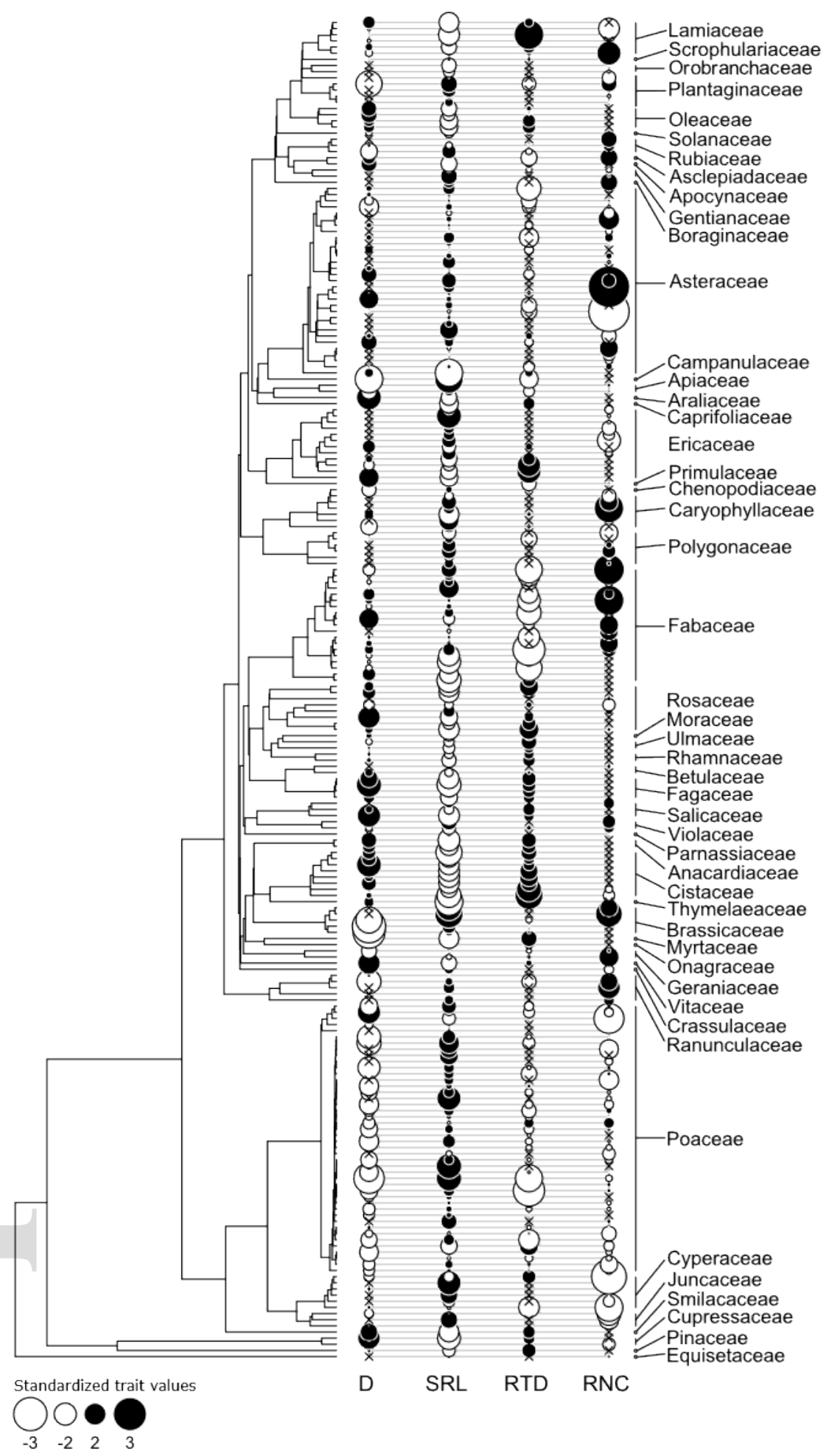

Figure 1: Phylogeny of the 249 species of this study (only family names are displayed). Estimated values of the four functional traits (Best Linear Unbiased Predictor estimated by mixed models) are represented at the tips of the phylogeny (in centred and standardised format). Black circles represent high values and white circles represent low values (magnitude is scaled by circle diameter). Missing trait values are 
represented by an X. D: mean root diameter; SRL: specific root length; RTD: root tissue density; RNC: 

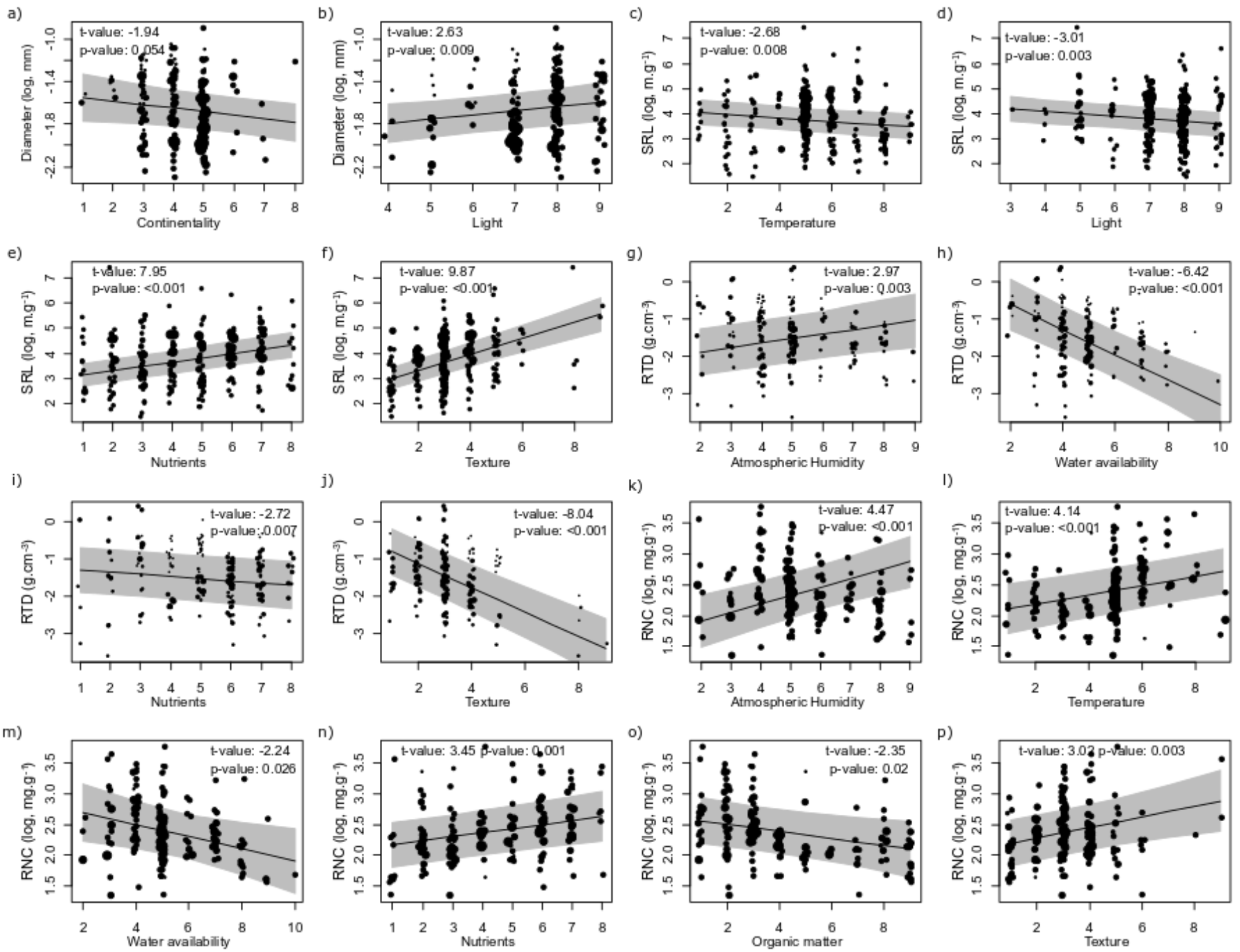

This article is protected by copyright. All rights reserved 
Figure 2: Biplots of relationships between ecological indicator values (EiV) and (phylogenetically corrected) trait values for those EiV that were retained in the best multivariate models (lowest AICc) explaining mean root diameter (a-b), specific root length (SRL) (c-f), root tissue density (RTD) (g-j) and root N

concentration (RNC) (k-p). Each point represents the Best Linear Unbiased Predictor (BLUP) of the phylogenetically corrected mean trait value of one species. The size of the points represents their weight within the model based on the inverse of the standard error of the estimation of the mean.

This article is protected by copyright. All rights reserved 
D

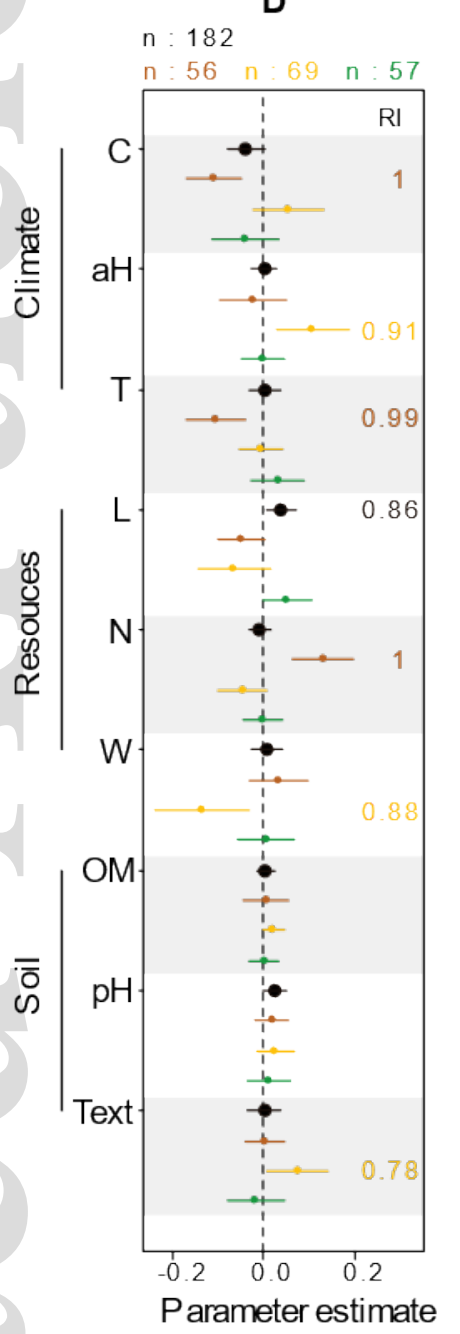

SRL

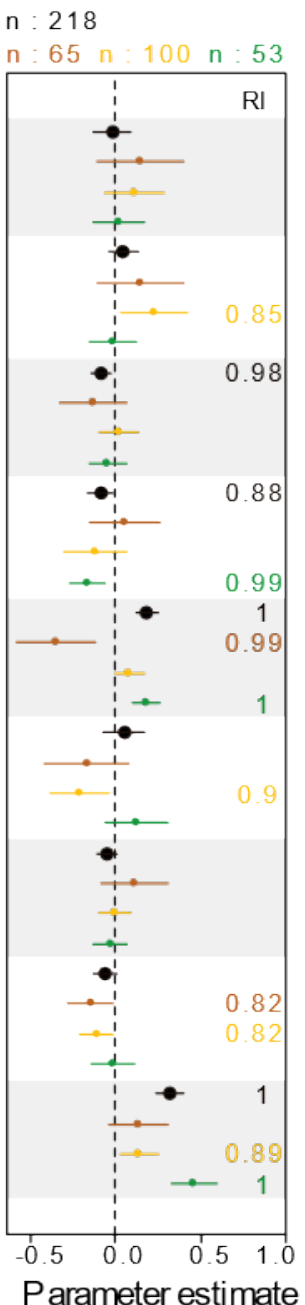

RTD

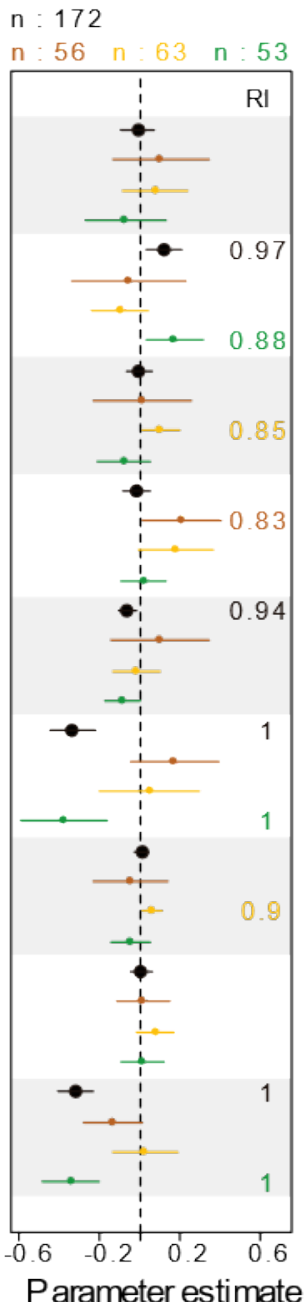

RNC

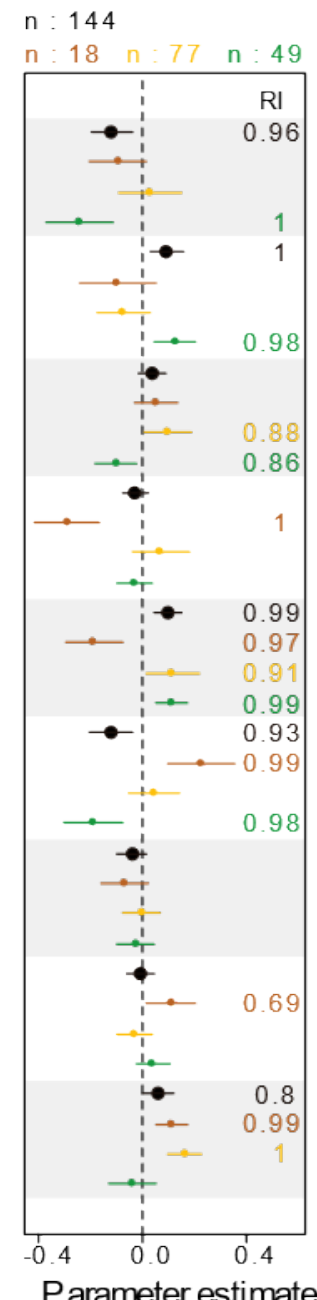

Figure 3: Effects of ecological indicator values (EiV) on fine-root traits across all species. Regression coefficients for models fitted separately for D: mean root diameter, RTD: root tissue density, SRL: specific root length and RNC: root $\mathrm{N}$ concentration (dots show average estimates, lines show $95 \%$ confidence intervals). Symbol colours differentiate between our analysis of the whole dataset (black) and its subsets: shrubs and trees only (brown), forbs only (yellow) and grasses only (green). The parameter estimates represent the magnitude of an ecological indicator effect on the standardised trait values. The RI (relative importance) varies from 0 to 1 and represents the sum of the Akaike weights of the models in which the ecological indicator appears (the more the RI value of an ecological indicator is close to 1 the more the models where it is represented have high Akaike weights, i.e. well represent the fitted data). EiV are separated into three groups: i) EiV related to climate, i.e. atmospheric moisture (aH), continentality $(\mathrm{C})$ and temperature (T), ii) EiV related to resource availability, i.e. light (L), nutrients $(\mathrm{N})$ and soil water (W) 


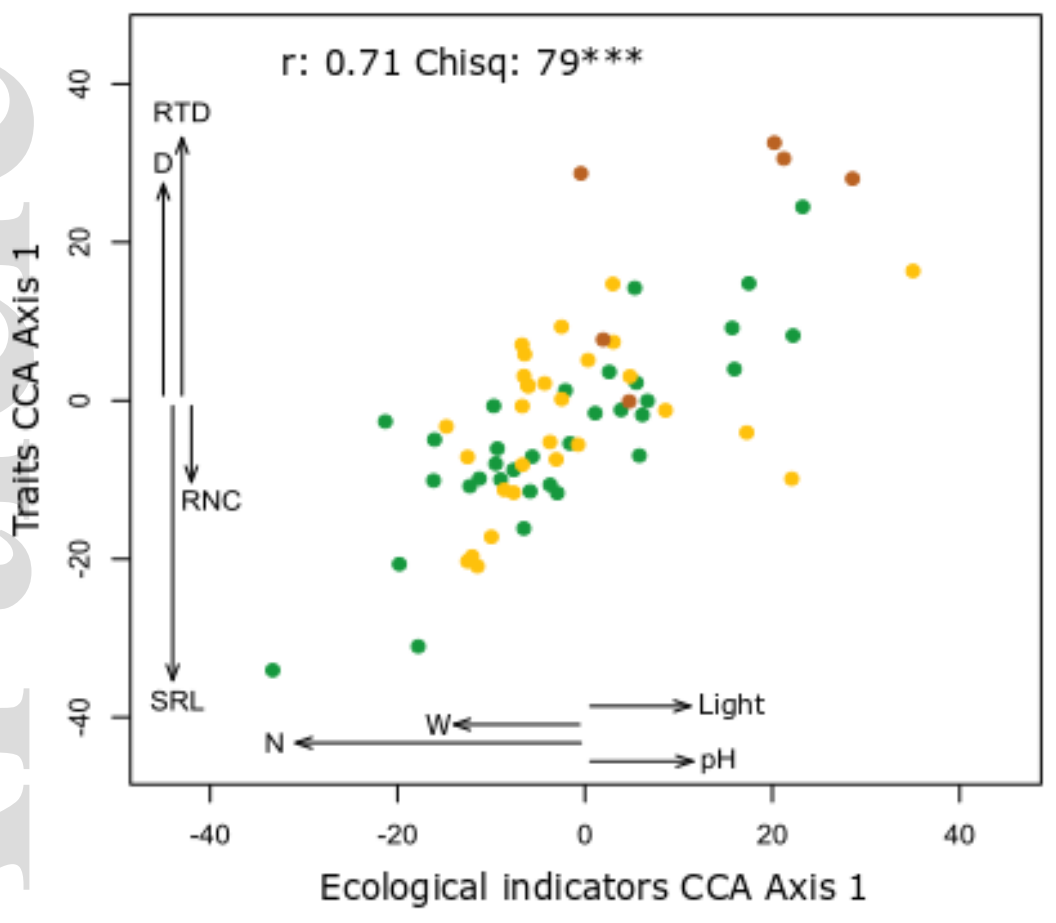

Figure 4: Relationship between species scores among the ecological indicator values (EiV; $\mathrm{x}$-axis) and root trait values (y-axis) from a phylogenetic canonical correlation analysis (pCCA). Brown points are shrub and tree species, yellow points are forb species and green points are grass species. The strength and direction of correlations between EiV and the $\mathrm{x}$-axis species scores, and between root traits and the $\mathrm{y}$-axis species scores, are represented by the direction and length of arrows. Only those variables significantly correlated with the axis species scores are represented. The significance of the relationship was assessed by Chi-square method, $\mathrm{n}=68$, $\mathrm{p}$-value $<0.001: * * *$. D: mean root diameter, RNC: root nitrogen concentration, RTD: root tissue density, SRL: specific root length. Light: light availability EiV, W: soil water availability EiV, N: nutrient availability EiV, pH: pH EiV. 